Case Report

\title{
Epidermoid Cyst in the Lateral Eyebrow (Frontozygomatic Suture) Region and Review of Literature
}

\section{Shetty Deepthi ${ }^{1}$, Shetty Prashanth ${ }^{2}$}

${ }^{1}$ Assistant Professor, Dept. of Oral \& M axillofacial Surgery, SDM College of Dental Sciences \& Hospital, Sattur, Dharwad, ${ }^{2}$ Reader, Dept. of Periodontics \& implantology, Yogitha Dental college and hospital, Khed, Ratnagiri, M aharastra.

*Corresponding Author : Shetty Deepthi, Department of oral and maxillofacial surgery, SDM college of dental sciences and hospital, Sattur, Dharwad - 580 009, Karnataka, India, M obile : +918105307631， E- mail : kdeepthishetty@ gmail.com.

Received

: 02.11 .2016

Review Completed : 09.05.2017

Accepted

26.05 .2017

Keywords : Epidermoid cyst, frontozygomatic suture

\begin{tabular}{|c|}
\hline Access this article online \\
\hline Quick Response Code \\
\hline
\end{tabular}

\begin{abstract}
Epidermoid cysts are non odontogenic, developmental pathologies occurring in the head and neck region with an incidence ranging from $1.6 \%$ to $6.9 \%$. Ambiguity about their exact pathogenesis exists and several theories have been postulated. Histologically they have cystic capsule lined by squamous epithelium without skin appendages. We have described a case of an epidermoid cyst in the lateral eyebrow region and its effective management with a brief review of literature.
\end{abstract}

\section{Introduction}

Epidermoid and dermoid cysts are developmental and non odontogenic cystic lesions derived from germinal epithelium [1, 2, 3]. It is suggested that these cysts are derived from epithelial remnants from the closure process of the first and second bronchial arches [3]. The incidence of such cysts in the head and neck region accounts for 1.6-6.9\% $[1,4]$. While a dermoid cyst has an epidermal lining with skin adnexa such as hair follicles and sebaceous and sudoriparous glands, the epidermoid cyst contains no such adnexa [2,3]. We report a case of an epidermoid cyst in the lateral eyebrow or frontozygomatic suture region and brief review of literature.

\section{Case report}

A 55 year old male patient reported to our institution for routine dental check up. On Extra oral examination there was a solitary well defined swelling in the left frontozygomatic region measuring approximately $2 \times 1.8 \mathrm{~cm}$ in diameter, soft cystic in consistency, freely movable and not fixed to the underlying structures and was completely asymptomatic [Fig.1]. Initial diagnosis of dermoid or epidermoid cyst was made. Patient expressed his desire to get it removed for aesthetic reasons. Patient had no significant medical and family history. Routine hematological tests were within normal limits. $2 \%$ lignocaine with adrenaline was infiltrated around the swelling after taking aseptic precautions. Entire cyst was removed using an elliptical incision and gross specimen was soft in consistency which contained whitish cheesy material [Fig.2]. Closure was achieved using 5-0 prolene sutures [Fig.3]. Histopathologial examination revealed a cystic cavity lined by stratified squamous epithelium and surrounded by a connective tissue capsule. The cystic cavity was filled with desquamated keratin and the connective tissue showed a chronic inflammatory response [Fig.4]. Hence a final diagnosis of epidermoid cyst was made. Post operative healing was uneventful with no signs of recurrence. 


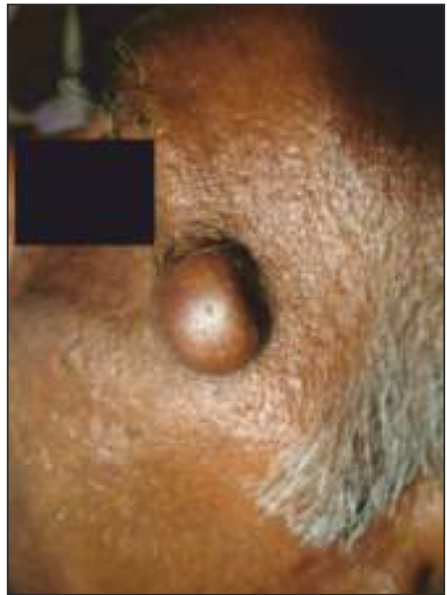

Fig 1 : Preoperative photograph

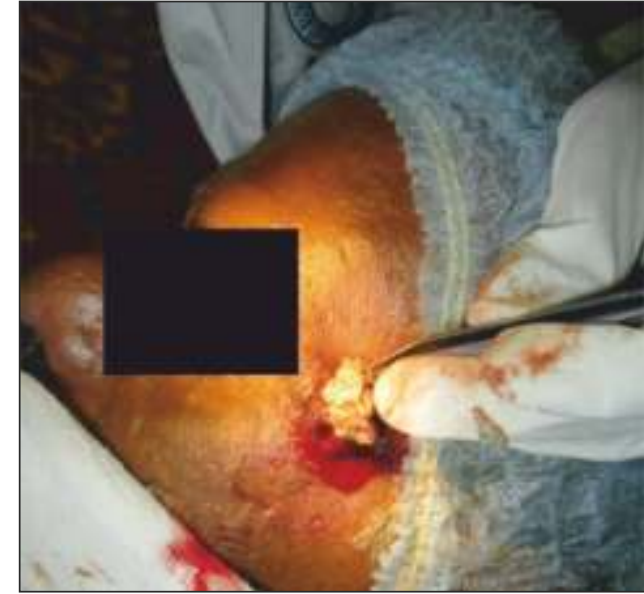

Fig 2 : Gross specimen

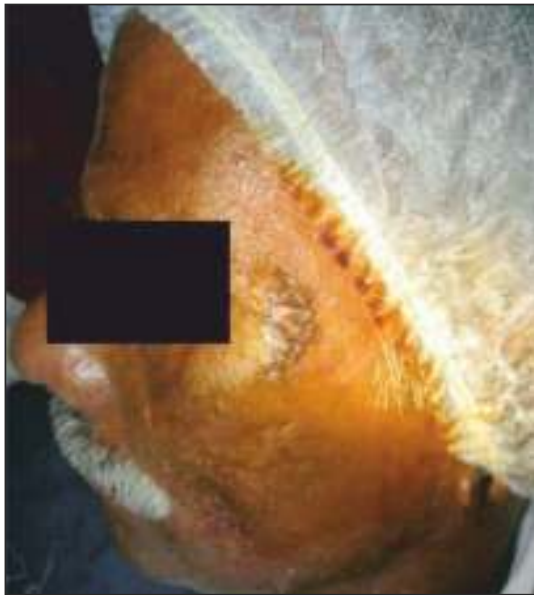

Fig 3 : Closure of the wound

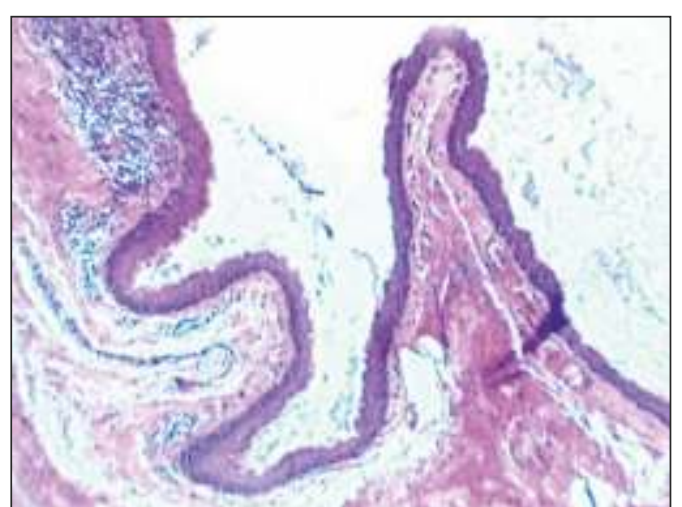

Fig 4 : Photomicrograph- H\&E stain $10 \mathrm{X}$

\section{Discussion}

Epidermoid cysts are cystic malformations lined with squamous epithelium. Most of the cases have been noticed in ovary and in testicles (80\%), with a particular predilection for the areas where embryological structures merge themselves. Head and neck accounts for about 1.6$6.9 \%$ and within the oral cavity they represent just $0.01 \%$ of all the cysts of the oral cavity. The head and neck sites affected most frequently with cutaneous cysts were the scalp (34\%), neck (18\%), periorbital area (17\%), cheeks \& lips (16\%), periauricular area (9\%), and nasal area (including forehead $(6 \%)^{[1,2]}$ M ore than half of these lesions are localized in the upper-orbital quadrant [6]. These cysts occur most often in patients in their second or third decade of life. It occurs more commonly in men than women in the ratio $3: 1$, with mean age of 28 years [1, 7]. Gardner syndrome is an exception, where the average age of incidence is 13 years [1].
Epidermoid cysts are rare lesions of questionable etiology. The most popular theory is the epithelium being sequestered in lines of fusion of embryonic processes as a result of epithelial tissue being traumatically implanted in utero or due to the traumatic implantation of epidermal elements in the dermis [1,2]. Epidermoid cysts can be either primary (congenital) or secondary cysts. Primary lesions are choristomas that involve displacement of epithelial elements during closure of the neural groove or other epithelial fusion lines between the third and the fifth weeks of gestation. Secondary epidermoid cysts result from post traumatic implantation of surface epithelium [5, 6].

Epidermoid cysts are slowing growing and usually asymptomatic, but they may become inflamed or secondarily infected, resulting in pain and tenderness. Clinically it may present as a round, firm, mobile flesh colored to yellow or whitish subcutaneous nodules of variable size. A central pore or punctum with thick cheesy material may be expressed. In a study from Indian population, $63 \%$ of the cysts showed melanin pigmentation [1]. Clinically epidermoid cysts are divided into superficial (simple) and deep (complicated) cysts. Because of their superficial localization, superficial cysts rarely develop complications and therefore are easily handled surgically. However, they rupture easily during surgical removal. Deep epidermoid cysts are described as a slow growing mass which enlarges during lifetime. They can break through any bony suture of the orbit into the 
temporal cavity, sinuses, or even intracranial cavity. They present in a variety of ways depending upon the suture of origin, size, rate of growth, and correlation to adjacent structures $[5,6]$. Although the epidermoid cyst rarely discloses malignancy, isolated cases of premalignant and malignant conditions (Bowen's disease, Paget's disease, squamous cell carcinoma and mycosis fungoides) have been found in their walls $[1,2]$.

M eyer classified cysts of the floor of the mouth into three groups namely Epidermoid, Dermoid and Teratoma. Histologically midline cysts of the floor of the mouth are divided into epidermoid cysts which consist of an epithelial lined wall that may be partly keratinized; without skin appendages; dermoid cysts, which show evidence of skin appendages such as hair follicles, hair, sweat and sebaceous glands; and teratomas which contain, in addition to skin appendages, mesodermal elements like bone, muscle, respiratory and gastrointestinal tissues and a fibrous capsule. The later type may have malignant potential $[2,4]$.

Epidermoid cysts have thin squamous lining because of lack of dermal appendages, which rarely contains calcifications. These cysts contain debris from the

\section{References}

1. Sunil S, Oommen N, Rathy R, Rekha VR, Raj D, Sruthy VK. Epidermoid cysts of head and neck region - Case series and review of literature. Int. J. Odontostomat. 2014; 8(2):165-169.

2. Ozan F, Polat HB, Ay S, Goze F. Epidermoid Cyst of the Buccal M ucosa: A Case Report.J Contemp Dent Pract. 2007 M arch;(8)3:090-096.

3. Correa M SNP, Fonoff RDN, Ruschel HC, Parizotto SPCDOL, Correa FNP. Lingual Epidermoid Cyst: Case Report in an Infant. Pediatr Dent. 2003;25:591-593.

4. Bhandary SK, Bhat V, Shenoy SM . Sublingual epidermoid cyst-a case report. Health. 2010;2(6):613-614.

5. Ahmed RA, Eltanamly RM. Orbital Epidermoid Cysts: A Diagnosis to Consider. Journal of Ophthalmology.2014:1-6

6. Veselinovic D, Krasic D, Stefanovic I, Veselinovic A, Radovanovic Z, Kostic A, Cvetanovic M . Orbital Dermoid and Epidermoid Cysts: Case Study. Srp Arh Celok Lek.2010 Nov-dec;138(11 12):755-759.

7. Romeo U, Palaia G, Giudice RL, Tenore G, Vecchio AD, Polimeni A. Epidermoid Cyst: Case Report of an Unusual Location. British Journal of Medicine \& M edical Research.2013;3(4):2085-2091. desquamation of the epithelial lining. The debris contains mainly keratin, a protein aceous material and some cholesterol. These are often described as pearly tumours because of the shiny smooth waxy character of the "dry keratin" on gross inspection [4].

The differential diagnosis for an epidermoid cyst should include developmental, neoplastic, and infectious lesions [2]. The developmental lesion was the most compatible category for this patient and the diagnosis between an epidermoid and dermoid cyst was initially considered and later confirmed through histopathological examination of the surgical fragment. The proposed treatment of epidermoid cysts is surgical removal. The cyst removal procedure was simple and effective, and its success was confirmed by the lack of postsurgical alterations and no recurrence of the lesion $[1,2,3]$.

To summarize we have described a case of epidermoid cyst in the lateral eyebrow (frontozygomatic suture) region, the treatment was planned considering the clinical features and patients aesthetic concerns. Though recurrence is very rare, follow up is required considering some reported cases of malignancy arising within the cyst walls and its proximity to important adjacent structures. 